
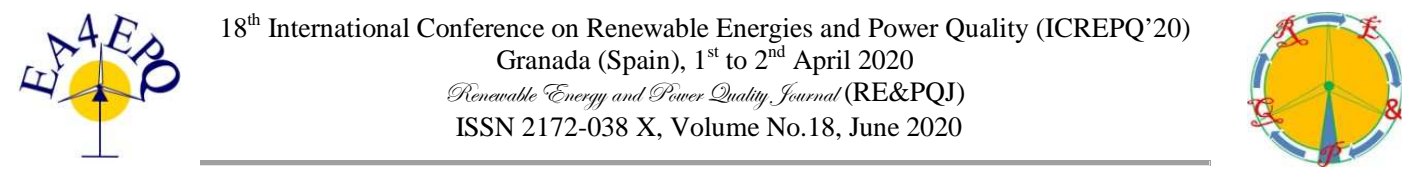

\title{
Interactive tool for the study of power signals generated by an inverter with PWM techniques.
}

\author{
Francisco Javier Jiménez Romero ${ }^{1}$, Francisco Ramón Lara Raya ${ }^{1}$, Francisco Manuel Álvarez Wic ${ }^{1}$ and \\ Antonio Cánovas Espinal ${ }^{2}$ \\ ${ }^{1}$ Department of Electrical Engineering \\ E.P.S.C., Córdoba University \\ Campus Rabanales - Edificio Leonardo da Vinci, 14071 Córdoba (Spain) \\ Phone/Fax number:+0034 957218 336, e-mail: fjjimenez@uco.es, el1laraf@uco.es, fmawic@gmail.com \\ ${ }^{2}$ Department of Electronics and Computer Engineering \\ E.P.S.C., Córdoba University \\ Campus Rabanales - Edificio Leonardo da Vinci, 14071 Córdoba (Spain) \\ Phone/Fax number:+0034 957218 356, e-mail: p12caesa@uco.es
}

\begin{abstract}
This work presents a new interactive tool for the study of the quality of power supply signals generated by an inverter. The tool has interactive elements to model and implement PWM techniques in a power inverter, it allows to modify any parameter of the PWM technique during the control of the inverter, being this a great advantage to make a lot of tests in a short time. In addition, the tool allows to design offline and simulate the behavior of the load that will feed the inverter. For the realization of the tool was used the graphic programming language Labview, for the control an Atmega328-PU microcontroller and an inverter Semikron-Semitech. A total of 1438 tests were carried out on a dhalander motor in 72 hours with two PWM techniques modelled with the tool, which made it possible to study the feed signal and the motor behaviour in the whole range of possible values that the parameters defining each PWM technique could take. The tool provides a great help to the experimental study of the quality of the power supply signals generated with an inverter for the power supply signal.
\end{abstract}

Key words. PWM, feed-inverter, interactive tool, power supply signal, Labview.

\section{Introduction}

The use of power inverters is very widely-used for a multitude of applications [1][2], among them, feeding electric motors [3][4] and most notably in those which, due to their construction characteristics [5], were designed to work within a reduced speed range, as in the case of the asynchronous induction motor, since the use of inverters allows some operating characteristics of these machines to be modified, for example, their speed [6][7].

The inverter transforms a DC voltage, which can come from the rectification of the grid voltage, into a voltage signal modulated in frequency whose waveform will depend on the pulse-generating signals that give rise to the output voltage. This way of generating signals is called pulse width modulation (PWM) and is commonly used in the control of electric motors [8][9][10].

The main objectives of the tool developed have been several. The first was to facilitate the testing of PWM
[11][12] techniques on electric motors, improving the ability to modify the parameters of the modulations generated by PWM signals during the tests, without having to stop the testing of the motor. The second is to facilitate the design and implementation of any PWM technique by using graphic controls and functions, as well as to modify the parameters of the techniques under study during the execution and testing of the motor by modifying the power signal during the test, as well as to simulate the electrical behaviour of the motor with the implemented PWM techniques and finally, the generation by means of the tool of a set of tests to be reproduced and subsequently analysed in the laboratory together with the inverter and the motor.

\section{Materials and methods}

\section{A. Materials}

The power equipment is a SEMIKRON SEMITECH inverter model SKM 50 GB 123D, it works with maximum values of $400 \mathrm{~V}$ and $30 \mathrm{~A}$, and a switching frequency of $20 \mathrm{kHz}$; it consists of a three-phase fullwave rectifier bridge, model $\mathrm{B} 6 \mathrm{U}$ developed by SEMIKRON and an insulated-gate bipolar transistor three-phase bridge, model B6CI developed by SEMIKRON

To record the electrical measurements was used FLUKE 435-Series II, which has 4 voltage and 4 current inputs with a sampling rate of 256 samples per cycle per input. Harmonic and inter-harmonic groups from 1 to 50 based on the standard IEC 61000-4-7 are considered.

The control equipment used in our study is responsible for controlling the inverter, loading the control vectors from the application, and applying the signals of the different techniques to be tested. This equipment consists of a microcontroller mounted on prototyping PCB, optocoupler circuit with $4 \mathrm{n} 35$ integrated circuits, and software for the generation and control of the PWM techniques created using Labview 2009 with the National 
Instrument graphic programming language widely used in a wide range of applications thanks to its versatility [13][14][15] and a own API for the communication microcontroller-Labview [16].

The motor used in our experimental setup is a three-phase induction motor with a squirrel cage, Dahlander type, which can be used to select the number of poles, thus changing the turning speed without modifying the signal frequency. The materials used to realize the tests are shown in Fig.1.

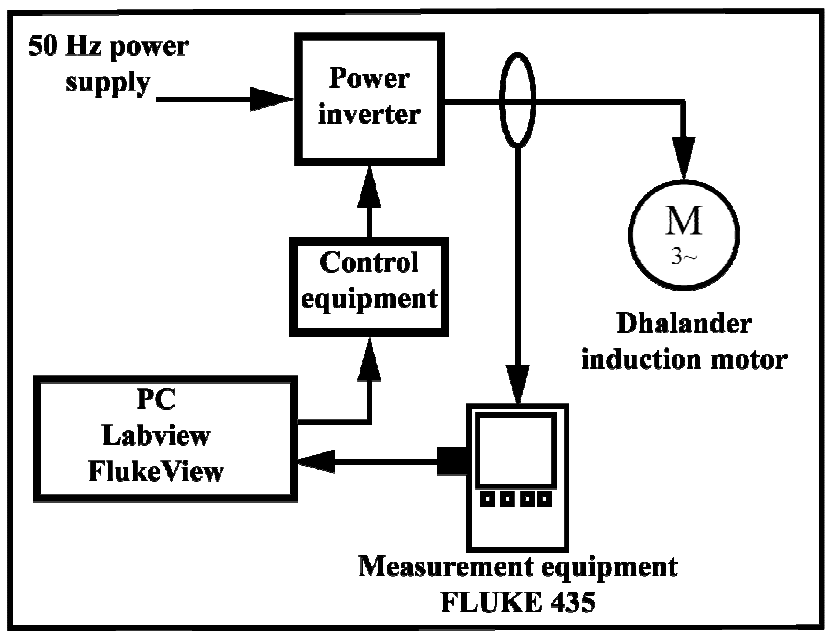

Fig.1. Setup for experimental tests.

\section{B. Interactive tool}

The interactive tool presented in this paper is formed by five main panels as shown in Fig.2. The functions of each panel have been grouped to facilitate the process of design, implementation, simulation and testing of PWM techniques.

The panels ' $a$ ' and 'b' shown in Fig.2 are used to define the PWM technique and interactively modify the control parameters of the implemented technique using the graphic controls. In the main panels 'c', 'd' and 'e' the simulation of the inverter power supply signal and the simulation of the load behaviour is displayed, for this work an induction motor has been used.

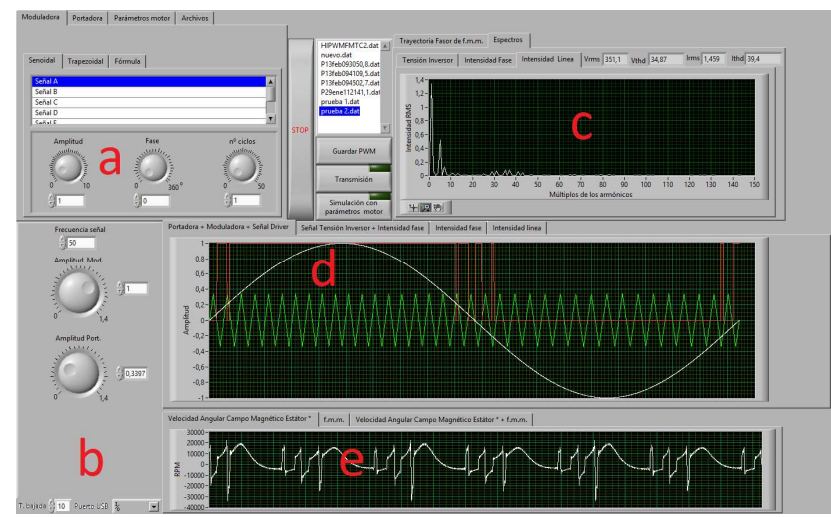

Fig.2 Main panels of the interactive tool

The procedure used to carry out the experimental tests with the interactive tool consists of three main parts. The first consists of implementing the PWM technique using the main panels 'a' and 'b' (Fig.2). During the implementation phase it is possible to interactively see the generation of the power signal in the main panel ' $d$ ' to check the correct implementation. Finally, the PWM technique implemented in the inverter is applied, interactively modifying the values of the control parameters while the load is being fed. In this last phase, the power supply signal for each value of the control parameter taken for the PWM technique has been recorded using the FLUKE 435-Series II measuring instrument. Subsequently, the implemented PWM technique is studied.

\section{Techniques PWM}

The modulation techniques employed in this study to regulate the supply of the electrical machines have been studied in previous research; these include Slope Pulse Width Modulation (SLPWM) [12] uses a trapezoidal wave to define the modulating wave as well as a discontinuous sinusoidal wave to generate the carrier wave. The carrier frequency is controlled using parameter $\mathrm{k}$, $(\mathrm{k} \mu$ times that of the modulating waveform, where $\mu$ is another control parameter), which, in turn, allows for the adjusting of the frequency modulation order. These techniques have their own objectives. For example, the SLPWM technique aims to achieve good wave quality, albeit using lower modulation indexes. The HIPWMFMTC2 [11] technique is aimed at reducing noise originating inside an electric motor. From the both PWM techniques, the level of harmonic distortion is studied according to the value of its control parameters.

\section{Experimental data}

In order to obtain a representative sample of the tests, in addition to considering the possible values of each parameter for each of the PWM techniques, different values of the modulation index have been used $(M=5,7$, $9,11,13,15,17,19$ and 21). The number of poles was also considered ( $\mathrm{p}=2,4,6$ and 12). The possible combinations for each PWM technique, modulation index, values of its control parameters and the number of poles of the induction motor were used in the study.

The values obtained for the control parameters for the SLPWM technique are shown in Table I. Each of these combinations were used for $\mathrm{p}=2,4,6$, and 12 , resulting in a total of 394 tests. 
Table I. - Values of the ' $k$ ' control parameters of the SLPWM technique

\begin{tabular}{|c|c|}
\hline $\mathrm{M}$ & $\mathrm{k}$ \\
\hline 5 & $-1.74,-1.64,-1.54,-1.44,-1.34,-1.24,-1.14,-1.04,-$ \\
& $0.94,-0.84,-0.74$ \\
\hline 7 & $1.24,1.34,1.44,1.54,1.64,1.74,1.84,1.94,2.04,2.14$, \\
& 2.24 \\
\hline 9 & $-2.74,-2.64,-2.54,-2.44,-2.34,-2.24,-2.14,-2.04,-$ \\
& $1.94,-1.84,-1.75$ \\
\hline 11 & $2.25,2.35,2.45,2.55,2.65,2.75,2.85,2.95,3.05,3.15$, \\
& 3.24 \\
\hline 13 & $-3.74,-3.64,-3.54,-3.44,-3.34,-3.24,-3.14,-3.04,-$ \\
& $2.94-2.84,-2.75$ \\
\hline 15 & $3.25,3.35,3.45,3.55,3.65,3.75,3.85,3.95,4.05,4.15$, \\
& 4.24 \\
\hline 17 & $-4.74,-4.64,-4.54,-4.44,-4.34,-4.24,-4.14,-4.04,-$ \\
& $3.94,-3.84,-3.75$ \\
\hline 19 & $4.25,4.35,4.45,4.55,4.65,4.75,4.85,4.95,5.05,5.15$, \\
& 5.24 \\
\hline 21 & $-5.74,-5.64,-5.54,-5.44,-5.34,-5.24,-5.14,-5.04,-$ \\
& $4.94,-4.84,-4.75$ \\
\hline
\end{tabular}

In the HIPWM-FMTC2 modulation technique, the control parameter is the angle $\alpha$, which takes values between $17^{\circ}$ and $45^{\circ}$, in $1^{\circ}$ increments for the tests. The number of tests per $\mathrm{M}$ value is 29 with 9 and 4 possible combinations based on $\mathrm{M}$ and number of poles, respectively; therefore, 1044 tests were performed in total.

With each test a set of data is obtained consisting of the number of poles of the electric induction motor ( $p)$, the modulation index of the PWM technique (M), the values of the control parameters of the PWM technique used and the electrical values measured by the network analyser FLUKE 435.

\section{Result}

With all the tests carried out, a detailed study can be made of the behaviour of the PWM technique according to its control parameters.

Fig. 3 shows how the total harmonic distortion in voltage in the SLPWM technique depends on the modulation index to a greater extent than on its control parameter $k$. The total harmonic distortion in voltage in the SLPWM technique depends on the modulation index to a greater extent than on its control parameter $k$. The total harmonic distortion in voltage in the SLPWM technique depends on the modulation index to a greater extent than on its control parameter $\mathrm{k}$.

The total harmonic distortion in voltage in the HIPWMFMTC2 technique does not only depend on the modulation index.Fig. 4 shows how the control parameter $\alpha$ and the value of $\mathrm{M}$ at the total distortion level. For example, in order to maintain a total harmonic distortion level of $25 \%$, the value of $\mathrm{M}$ must be increased by one for each $5^{\circ}$ of the $\alpha$ angle.

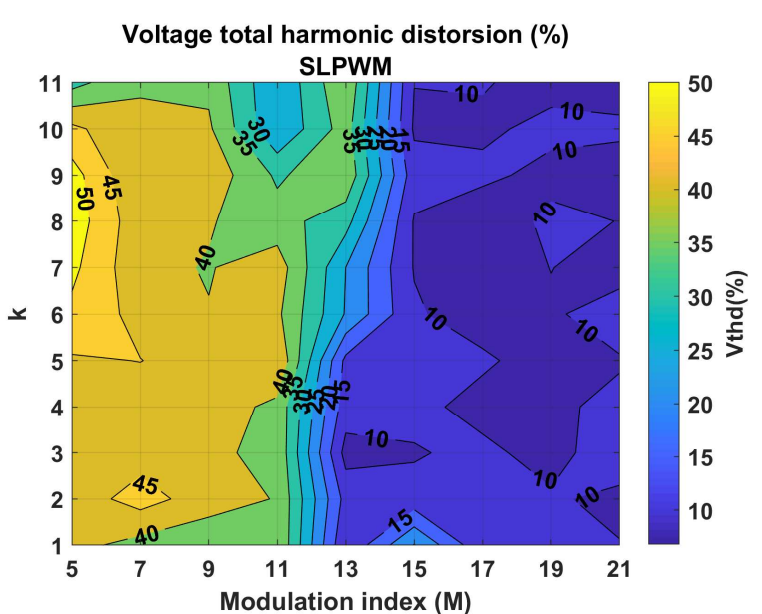

Fig.3 Total harmonic distortion of voltage in the SLPWM technique as a function of the control parameter $\mathrm{k}$.

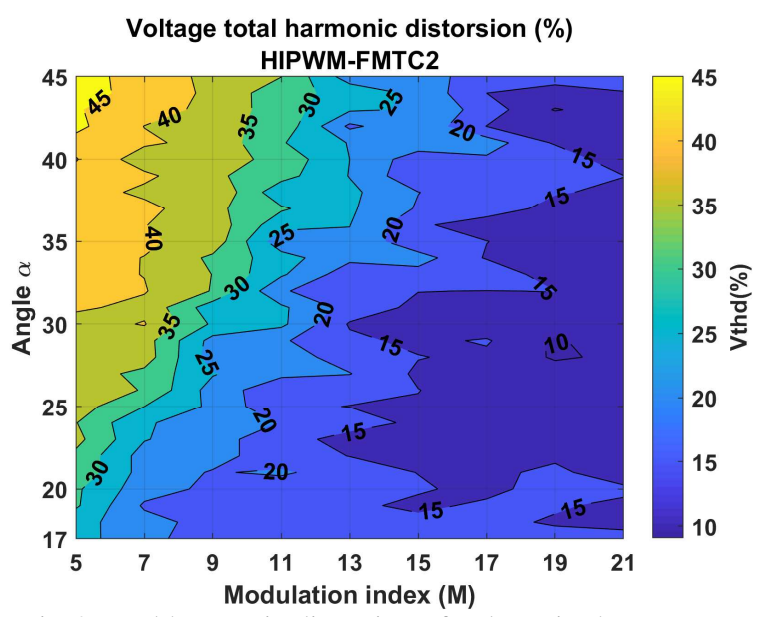

Fig.4 Total harmonic distortion of voltage in the HIPWMFMTC2 technique as a function of the control parameter $\alpha$

Fig.5 shows the total harmonic current distortion level for SLPWM technique and 2 pole configurations, this shows the low dependence of the control parameter value, except in the zone between $\mathrm{k}=4$ and $\mathrm{k}=11$ with $\mathrm{M}<7$.

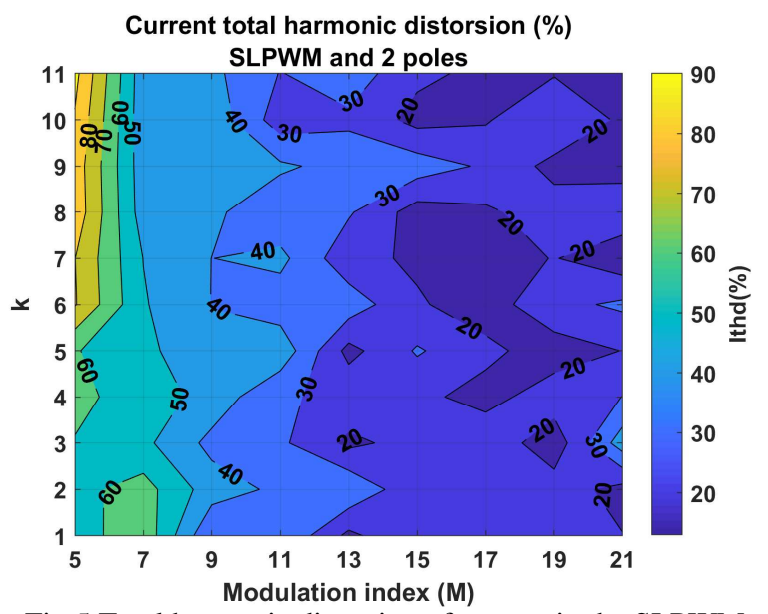

Fig.5 Total harmonic distortion of current in the SLPWM technique as a function of the control parameter $\mathrm{k}$ and 2 poles

Fig.6-8 shows that the distribution of harmonic levels for the remaining configurations of number of poles 4, 6 and 12 is similar that for 2 poles. The difference between the four number of pole configurations is the level of 
harmonic distortion in current, being higher for 2 poles and lower for 12 poles.

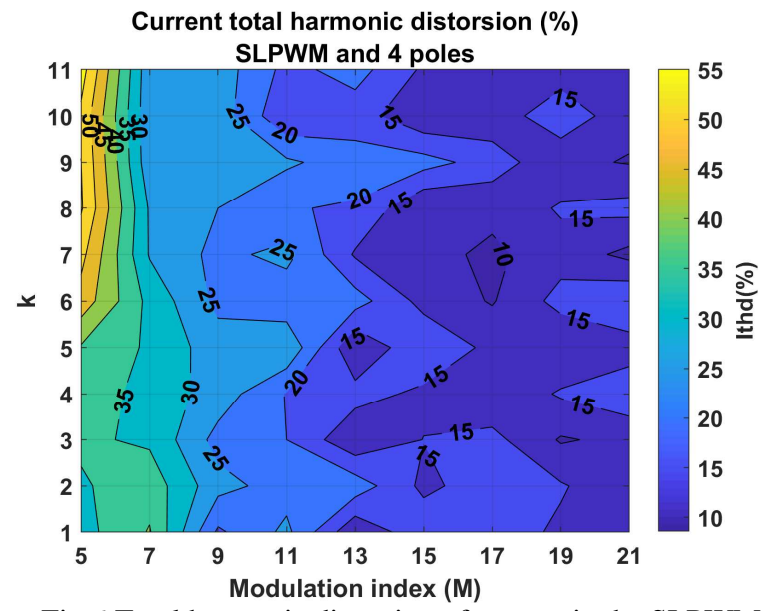

Fig.6 Total harmonic distortion of current in the SLPWM technique as a function of the control parameter $\mathrm{k}$ and 4 poles

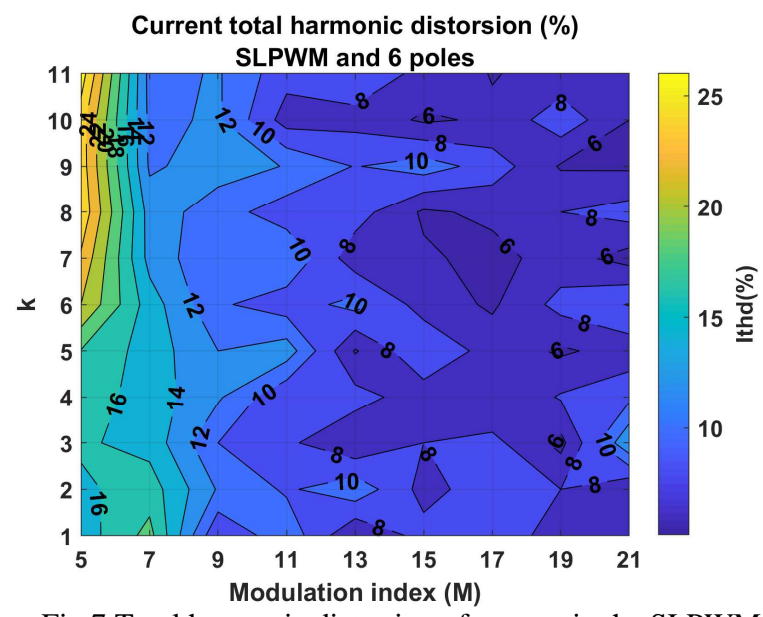

Fig.7 Total harmonic distortion of current in the SLPWM technique as a function of the control parameter $\mathrm{k}$ and 6 poles

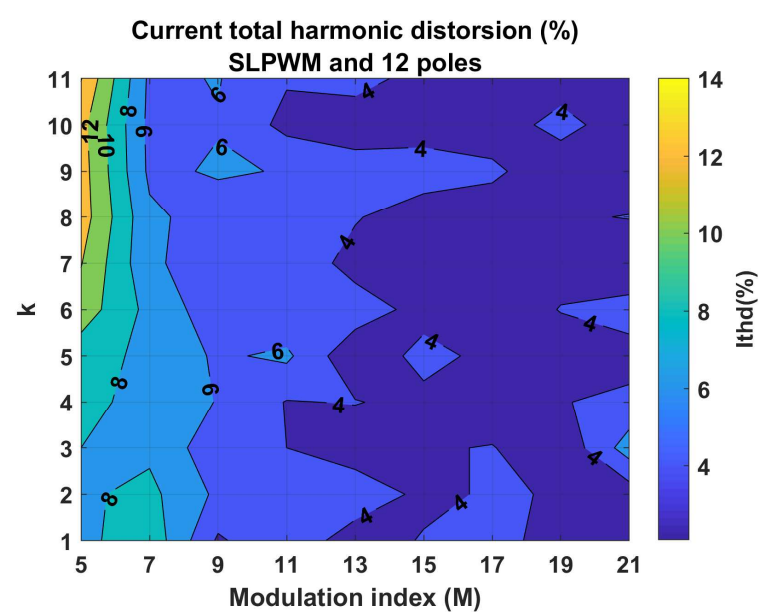

Fig.8 Total harmonic distortion of current in the SLPWM technique as a function of the control parameter $\mathrm{k}$ and 12 poles

In Fig. 9 it can be seen how the distribution of the current harmonics for HIPWM-FMTC2 and 2 poles. It depends on the control parameter $\alpha$ and the value of $M$. For all configurations of number of poles (Fig.9-12) the optimum value for the alpha control parameter $\alpha$ is within the range of $25^{\circ}$ and $30^{\circ}$. The values of $\mathrm{M}$ that most influence the level of harmonic distortion in current are between 5 and
13. For values of $M>13$ the harmonic distortion in current depends exclusively on the alpha value.

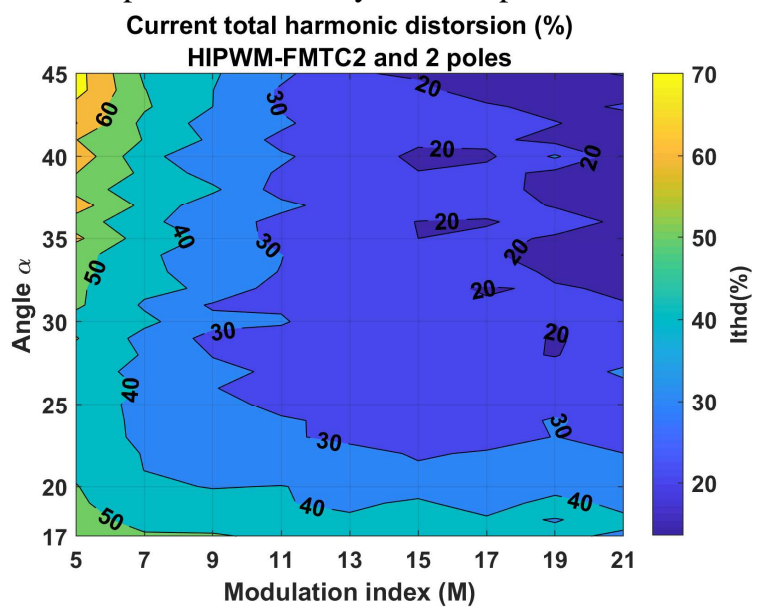

Fig.9 Total harmonic distortion of current in the HIPWM-

FMTC2 technique as a function of the control parameter $\alpha$ and 2 poles

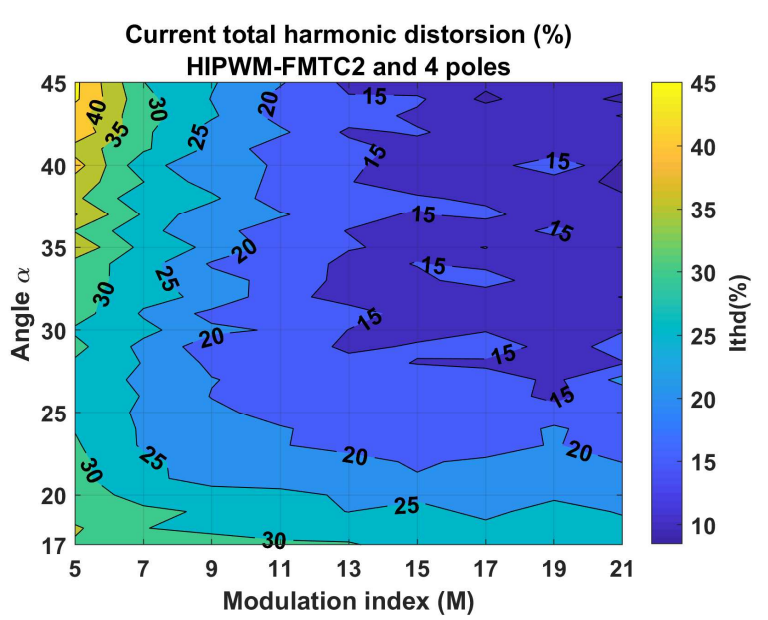

Fig.10 Total harmonic distortion of current in the HIPWM-

FMTC2 technique as a function of the control parameter $\alpha$ and 4 poles

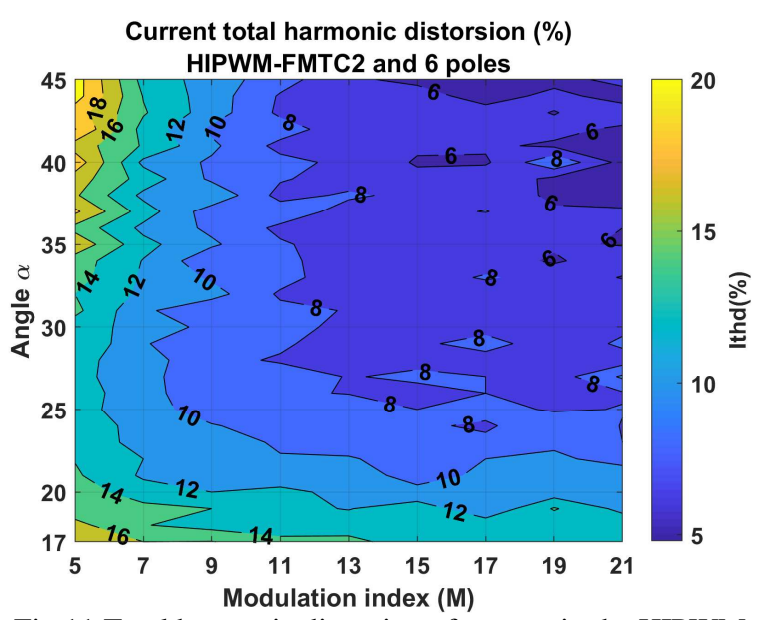

Fig.11 Total harmonic distortion of current in the HIPWM-

FMTC2 technique as a function of the control parameter $\alpha$ and 6 poles 
The distribution of the current harmonics in the HIPWMFMTC2 technique for the four pole number configurations is maintained, varying between each pole number configuration the magnitude of the current harmonics.

The current harmonics vary from $20 \%-70 \%$ for 2 poles (Fig.9), 10\%-45\% for 4 poles (Fig.10), 5\%-20\% for 6 poles (Fig.11) and 2\%-10\% for 12 poles (Fig.12).

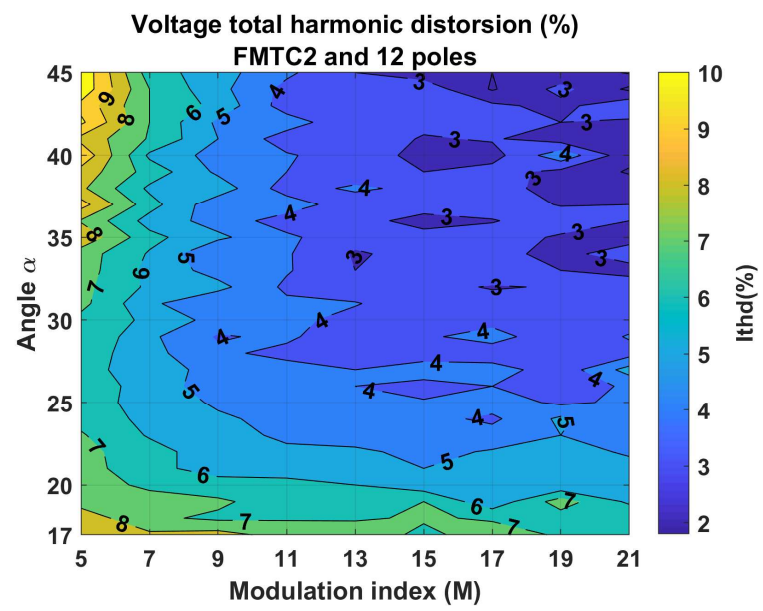

Fig.11 Total harmonic distortion of current in the HIPWM-

FMTC2 technique as a function of the control parameter $\alpha$ and 12 poles

\section{Conclusion}

The interactive tool facilitates the study of PWM techniques. In this way it is possible to make an analysis of the behaviour of the PWM techniques according to the values of their control parameters and the feed signal generated by the inverter.

Experimental tests are interactive and dynamic because the value of the control parameters of the PWM techniques tested can be modified interactively, obtained a wide range of information on the behaviour of the PWM technique. Also, thanks to be an interactive tool it allows to implement the PWM techniques by means of simple interactive controls.

Due to the amount of data obtained, it is possible to perform an experimental analysis of the PWM technique studied, compare it with other PWM techniques and different configurations of the load that feeds the inverter, which for this work has been the induction motor.

\section{References}

[1] A. Pourfaraj, M. Monfared, and H. Heydari-Doostabad, "Single-Phase Dual-Mode Interleaved Multilevel Inverter for PV Applications," IEEE Trans. Ind. Electron., vol. 67, no. 4, pp. 2905-2915, 2020.

[2] A. Arikesh and A. K. Parvathy, "Modular multilevel inverter for renewable energy applications," Int. $J$. Electr. Comput. Eng., vol. 10, no. 1, pp. 1-14, 2020.

[3] S. Bernet, "Recent developments of high power converters for industry and traction applications," IEEE Trans. Power Electron., vol. 15, no. 6, pp. 1102-1117, 2000.

[4] E. Persson, "Transient Effects in Application of PWM Inverters to Induction Motors," IEEE Trans. Ind. Appl., vol. 28 , no. 5, pp. 1095-1101, 1992.

[5] R. Lara, R. Jiménez-Romero, F. Pérez-Hidalgo, and M. D. Redel-Macías, "Influence of constructive parameters and power signals on sound quality and airborne noise radiated by inverter-fed induction motors," Meas. $J$. Int. Meas. Confed., vol. 73, pp. 503-514, 2015.

[6] Y. Zhang, P. Huang, and H. Yang, "Hardware-in-theLoop Real-time Simulation for Speed-Sensorless Vector Control of High-Power Induction Motor," in 2019 22nd International Conference on Electrical Machines and Systems, ICEMS 2019, 2019.

[7] A. L. Sheu and T. A. Adagunodo, "Performance Evaluation of Inverter-equipped Drive to Regulate the Speed of Motor and Cooling Output of Air Conditioner," in Journal of Physics: Conference Series, 2019, vol. 1299, no. 1.

[8] V. Anantha Lakshmi, V. C. Veera Reddy, and M. Surya Kalavathi, "Space vector based hybrid PWM algorithm for direct torque controlled induction motor drives for reduced common mode voltage," J. Electr. Eng., vol. 12, no. 3, pp. 65-72, 2012.

[9] S. K. Dash and R. S. Kaarthik, "Independent Speed Control of Two Parallel Connected Split-Phase im with a Common DC Link and Inverter," IEEE Trans. Power Electron., vol. 34, no. 10, pp. 9957-9965, 2019.

[10] M. U. Kiran, S. S. Nawaz, and P. V. S. G. Prasad, "Induction motor speed control fed by an inverter coupled with DSPACE controller," Int. J. Innov. Technol. Explor. Eng., vol. 8, no. 12, pp. 3697-3701, 2019.

[11] A. Ruiz-González, M. J. Meco-Gutiérrez, F. VargasMerino, F. Pérez-Hidalgo, and J. R. H. Larrubia, "Shaping the HIPWM-FMTC strategy to reduce acoustic noise radiated by inverter-fed induction motors," in 19th International Conference on Electrical Machines, ICEM 2010, 2010.

[12] F. Vargas-Merino, M. J. Meco-Gutierrez, J. R. Heredia-Larrubia, and A. Ruiz-Gonzalez, "Low Switching PWM Strategy Using a Carrier Wave Regulated by the Slope of a Trapezoidal Modulator Wave," IEEE Trans. Ind. Electron., vol. 56, no. 6, pp. 2270-2274, 2009.

[13] N. L. Hinov and T. H. Hranov, "LabVIEW Based Control System for PWM DC-DC Converters," in 2019 28th International Scientific Conference Electronics, ET 2019 - Proceedings, 2019.

[14] Y. Boukadida, F. Marignetti, V. Fiengo, R. D. Stefano, and C. Ungaro, "Labview FPGA-based space vector modulation control of 3-phase voltage source inverter," in 2019 14th International Conference on Ecological Vehicles and Renewable Energies, EVER 2019, 2019.

[15] S. A. Prakash, R. Aravind Mohan, R. M. Warrier, R. Arun Krishna, A. Sooraj Bhaskar, and A. K. Nair, "Real time automatic speed control unit for vehicles," in Proceedings of the International Conference on ISMAC (IoT in Social, Mobile, Analytics and Cloud), ISMAC 2018, 2019, pp. 157-161.

[16] F. J. Jimenez, F. R. Lara, and M. D. Redel, "API for communication between Labview and Arduino UNO," IEEE Lat. Am. Trans., vol. 12, no. 6, pp. 971-976, 2014. 